\title{
Arab Women Using Internet: Case Study the U.A.E and Oman
}

Amina K Aldhaheri*

Department of Mass Communication, United Arab Emirates University, UAE

\begin{abstract}
There are trends showing that women using internet around the world is increasing. A new study confirms that Arab women are highly proficient in the use of the internet. This study is investigating the online attitudes and behaviors of Arab women using the internet, case study is UAE and Omani women. This is a comparative study which compares the use of internet of the UAE and Omani women.

The study conducted between 2007- 2008 and it's a descriptive study that aims to describe and investigate the way that Arab women use the internet in two countries (the UAE and Oman). This study is important because it will help to understand the phenomenon of Arab women using internet. Studies of Arab women using internet are rare. In addition, the importance of this study is to lead to deep investigation in the future in the area of Arab women using internet.

The study found that there are no big differences between the UAE women and Omani women in using internet. The study has shown that both women are using internet every day between 1-4 hours daily. Both women use internet for different reasons such as sending and receiving e-mails, to find some information, to read newspaper, to chat with friends, and to learn some skills. The study found that there is a difference in using internet for expressing feeling between UAE women and Omani women. $80 \%$ of UAE women are using internet to express their feeling while $30 \%$ of women are using internet for the same reason. Both women are agreed that using internet helped them to understand women issues around the world.
\end{abstract}

\section{Introduction}

Rapid and successive developments in telecommunications and information technology have opened new horizons for individuals all over the world irrespective of their societies, cultures and scientific potentials. These transformations have led to the emergence of many up-to-date technological systems including the Internet, which has become a new and easy means of communications for individuals, groups and institutions in modern societies. For Arab societies, Gulf Arab countries score higher in the use of the Internet. This new means of communications and knowledge prompted researchers to study it and determine the profiles of its users and their trends, especially women, after international studies have already shown that women constitute a growing majority of the users of the web. A report published by E-Marketing in 1999, showed that women constitute $46 \%$ of Internet users in the United States. Meanwhile, Net Smart Company published some figures showing that $58 \%$ of new internet users are women. Therefore, we see that the number of women who use the Internet is increasing rapidly. What about women in the Arab World? Only few studies and statistic cover the use of Internet by women in the Arab World. Hence, this study would deal with Arab women and the Internet. The study focuses on two Arab countries, namely, The United Arab Emirates and the Sultanate of Oman. It would serve as a case study and an example of use of Internet by Arab women in general.

\section{The Importance of the Study}

The importance of this exploratory study lies in the following aspects:

1- There are only few studies that deal with the issues of women in the Arab World. There is also a lack in studies that cover the issues of women and technology, including the use of the Internet.

2- The results and conclusions of the study and the facts that would help in understanding the use of the Internet by an important segment of the Arab Society, i.e. women.

3- This study would open new horizons for scientific research in the
Arab society and the differences and similarities in women's use of the Internet in the Arab World.

4- This study is an attempt to know how women use the Internet and in which aspects. It could serve as a prelude to other studies on the possibility of using the web in support of women causes in the Arab World in general.

\section{Objectives of the Study}

The main objective of this exploratory study is to monitor, analyze and describe how Arab women use the Internet and determine the differences and similarities in this respect in the Arab societies of the United Arab Emirates and the Sultanate of Oman (the focus of the Study).

The study aims also at recognizing the websites, which are frequently visited by Arab women, the nature of information they search for and the most important issues that attract them. It also aims at determining and the extent of the benefit gained by women from the use of the internet and to what extent they use it to keep up to date on the causes of Arab women.

\section{Questions of the Study}

This is an exploratory and descriptive study. Therefore, it seeks to answer some questions without using preset hypotheses. The questions

*Corresponding author: Amina K Aldhaheri, Department of Mass Communication, United Arab Emirates University, UAE, Tel: +971 3 7136458; E-mail: Aminak2000@uaeu.ac.ae

Received June 05, 2012; Accepted June 19, 2012; Published June 21, 2012

Citation: Aldhaheri AK (2012) Arab Women Using Internet: Case Study the U.A.E and Oman. J Mass Commun Journalism 2:121. doi:10.4172/2165-7912.1000121

Copyright: (c) 2012 Aldhaheri AK. This is an open-access article distributed under the terms of the Creative Commons Attribution License, which permits unrestricted use, distribution, and reproduction in any medium, provided the original author and source are credited. 
of the study are as follows:

1- How Arab women use the Internet?

2- What are the websites, which are frequently used by Arab women?

3- What are the issues that concern women while using the Internet?

4 - Is there any difference between women's use of the Internet in the United Arab Emirates and the Sultanate of Oman?

5- What are the characteristics of the Arab women who use the Internet?

\section{Hypotheses of the Study}

1- Woman's use of the internet reduced the time allocated for watching television as a means of communication.

2- Woman's use of the Internet helped her acquire new skills.

3- Woman's use of the Internet increased her awareness of her social issues.

\section{Method of the Study}

The study relies on the comparative descriptive method as it aims at monitoring and analyzing the uses of Arab women of the Internet, and detecting the similarities and differences between the societies of the United Arab Emirates and the Sultanate of Oman- the focus of the study- in this respect. Therefore, the study was applied on the two Arab societies of the UAE and the Sultanate of Oman.

Descriptive research aims at describing the phenomenon that is to be studied in a detailed and accurate manner in order to facilitate its analysis and predict its development in the future. In this respect, researchers Dr. Ali Abdel Mo'ti and Mohammed Al-Seriaqosi [1] said that the most important objective of descriptive research is "1- to provide an accurate image of the characteristics of the phenomenon under study. 2- to collect information and data about the phenomenon and the facts, 3 - pave the way for conducting more research."

The researcher adopted the field survey method in this study. It is a well-known fact that field research is among the methods used in descriptive studies, with the objective being to collect information and facts required for studying and understanding the phenomenon under study. This method collects data about social, economic, cultural and political circumstances of a certain society. Such data can be collected based on a survey of all population or a sample representing the society under study only. The survey uses several tools, such as continuous observation, interviews, inspection and questionnaires, which are used in this study. Abdul Mo'ti said, "The questionnaire is part of the descriptive methodology, through which we can obtain accurate information related to the subject of the research."

\section{Sample of the Study}

The study covered 400 women, 200 for each country. The researcher used two types of samples. At the first stage, she used the quota sample as she allocated 200 types of forms for each society, while in the second stage, the researcher used the survey sample as these forms were distributed to working women randomly in various regions, cities and districts.

\section{Related Studies}

In view of the fact that studies on the internet in the Arab world are scarce and new let alone those that have dealt with Arab women and the Internet, the researcher found it difficult to find studies on the Arab woman and her use of the Internet. Therefore, most studies included in this part of the study were about the use of the web in the Arab world in general. They have also dealt with the patterns, motivations, and nature of this usage by several categories of the Arab society. These are as follows:

1- A study by researcher Ahmed Fahmi [2] entitled "The use by Egyptian youth of the Internet," which covered a group of youth at the age segment of 18-25 years, showed that the motives of youth in using the Internet are to obtain information. It also showed that $85 \%$ of those young men use the internet for more than a year, while $22 \%$ of them began using it three years ago.

2- Another study by researcher Nagwa Abdel Salam [3] entitled, "Patterns and motivations of using the Internet among the Egyptian youth" covered a group of young men aged 18-25 years. The researcher concluded that the main motives for using the Internet by those young men were to get information, entertainment, making friends, and keeping up to date with the developments in the world around them as well as spending their leisure time and getting to know all that is new in telecommunications sector.

3- A third study by researcher Mervat Mohamed Al-Tarabishi [4] entitled "The factors affecting Egyptian young men in visiting websites" covered a sample of 300 persons. The researcher concluded that $58.7 \%$ of those young men use the Internet regularly for entertainment purposes in the first place and for learning, culture, making friends and getting information about the global news and events in addition to work necessities and getting rid of boredom.

4- Meanwhile, the study conducted by researcher Sameh Abdel Raouf Taie [5] entitled "The use of the Internet in the Arab world" covered a sample of youth in Egypt, Saudi Arabia, Kuwait and Bahrain. The study concluded that $72.6 \%$ of the participants in the sample use the Internet. It also found that Internet cafes are the most frequented places for navigating the Internet followed by the house. The evening was the time used for visiting the Internet. Motives included getting information, followed by entertainment, spending leisure time and messaging.

5- In their study entitled "The effect of using the Internet on social isolation of Kuwaiti young men" [6], researchers Yaqoub Al-Kandary and Hamoud Al-Qash'an found that $75.8 \%$ of the sample use the Internet at home, and that it has its effect on the feeling of alienation and social separation. Therefore, it isolates them from the surrounding individuals either in the family or among friends and the social environment. The study has also found that there are no differences between males and females in the average use of the Internet among Kuwait university students.

6- Researcher Berlent Qabil has conducted a study [7] on the effect of personal characters on communication activities.

The researcher used a sample from four universities in Egypt, including Cairo University, Al-Azhar University, the American University in Cairo and Cairo International University. She concluded that $70 \%$ of the sample participants tend to use the Internet as a personal means of communication. They also use it for chatting and sending and receiving emails. $20 \%$ of the participants use the Internet for research and surfing. The study has also shown that there is a relationship between the level of happiness and the tendency to use the Internet as a personal means of communication. 
7- In his study entitled "the effect of the use of the Internet on values and moral ethics among university students" [8], researcher Amin Said Abdel Ghani concluded that the use of the Internet among Egyptian University students involves many risks, which include political, religious, health and ethical risks. The study has also stressed that pornographic websites on the Internet constitute the biggest risk with respect to those young men.

8- Meanwhile, researcher Hatem Mohamed Atef conducted a study entitled "The relationship between using the internet and cultural identity" [9]. He discovered that female secondary school students use the Internet more often than males. He also found that home the mostly used place for surfing the Internet followed by the club. However, the frequently visited websites include chat rooms, followed by musical and songs websites. The key motivations for using the Internet are to review emails, gain cultural knowledge, and get religious and artistic information.

9- Researchers Mohamed Qirat and Mohamed Ayesh [10] found in their study entitled "The uses of the Internet: Field study of UAE youth" that the relationship between the participants of the study sample and the Internet is very short because they began using it from 2-3 years. It is available for them at home. Very small percentage of them uses the Internet in cafes. They have also discovered that more than half of the participants use the Internet for one or two hours in the evening every day. The study has also concluded that the sample participants use the Internet for many reasons including reviewing email, entertainment, studying and scientific research. Around $18.4 \%$ of the participants have their own websites. Two thirds of them said they could not live without the Internet.

10- Meanwhile, in his study entitled "The UAE youth and the Internet: A field study on the habits of using the Internet and the effect on cultural behavior, Nasr Al- Al-Ayadi [11] concluded that the use of the Internet is subject to the economic and social framework. Therefore, chatting through the Internet plays a compensatory role because separating male and female students in the education system and the lack of opportunities for females and males to meet encourage the young men to chat in order to know each other. The use of the Internet by youth does not come at the expense of other means such as the television, newspapers, and the radio. It has not created any new habits other than those in advanced countries.

Besides these Arabic studies about the Internet, the researcher has managed to obtain some foreign studies that dealt with the same subject. It benefited from these studies in methodological and theoretical aspects of the study. These foreign studies include the following:

11- A study by Lauri M [12] entitled "A Uses and Gratifications Approach to Internet Use in Malta" concluded that the members of the sample use the Internet for 6-12 hours every week and that females use the Internet more than males. The motivations for using the Internet include fleeing the daily routine, making friends, obtaining information and entertainment. It also found that $35 \%$ of the sample participants use the Internet at home, $29 \%$ use it in the workplace and $8.8 \%$ of them use it at school.

12- Another study by New Hagen and Rafali [13] entitled, "Why Communication researchers should Study the Internet" reached some conclusions including the fact that the Internet is a means of communication with good concept, which include audiovisual aspects and it is fast in communication.

13- In his study [14] entitled "The use of the Internet and its effect on adults and teenagers," Imel S concluded that the use of the Internet is linked to the educational, economic and social standard and to the levels of the users. The study stressed the role of the Internet in creating the feelings of social isolation because it increases the feeling of alienation and separation from the surroundings.

All the above studies focused on the Internet and its uses amongst the youth in general. The present study focuses on the use of the Internet by Gulf Arab women in a case study of the United Arab Emirates and the Sultanate of Oman.

\section{Summary of the Study and Answers to its Questions}

This study aimed at monitoring and analyzing the use of the Internet by Arab women through studying the situation of women in the United Arab Emirates and the Sultanate of Oman. It attempted to know the websites, which are frequently used by women and the nature of information she looks for in the Internet and the differences between the two countries. The researcher arrived at several results that can be summarized in the following points:

\section{First}

There is no big difference between UAE and Omani women in their use of the Internet because both countries belong to the Arab and Islamic nation. They both have similar culture and traditions. They also have similar education levels for women. Therefore, there is some sort of intellectual closeness between them in addition to their geographic proximity and common border, which facilitated material, intellectual and cultural interaction between both societies in general.

\section{Second}

Women in both countries have the same pattern in using the Internet in terms of frequency, average and method of using it. As for the time of use, the researcher found that there is a little difference between both societies because $55 \%$ of UAE women prefer to use the internet in the evening, while $70 \%$ of their Omani counterparts use it in the morning.

This result would be natural if we compared between the tables of the places in which UAE and Omani women use the Internet. The study showed that $55 \%$ of UAE women use the Internet at home, while $75 \%$ of Omani women use at in the workplace. This is natural result because most Omani women are at work in the morning and use the Internet there. Furthermore, there is another factor behind Omani women's use of the Internet at work. It is the economic element. A simple comparison of the income tables shows that the income of UAE women is double that of the Omani women, which enable the former to pay the home service fees. A third factor lies in the fact that several Omani regions and states are not covered by the Internet because of rough topography, which makes it difficult to connect the service.

\section{Third}

As for the reasons purposes of using the Internet, the study showed that women in both countries use the Internet for several and diverse purposes. The percentage of use in the UAE and Oman looks similar in terms of performing jobs, reviewing email, reading newspapers, gaining information and acquiring skills. However, there is big difference between UAE and Omani women in terms of using the Internet to express private feeling. Some $80 \%$ of UAE women use the Internet for this purpose, while $30 \%$ of their Omani counterparts use it for the same purpose. This may be attributable to the fact that the Omani society still adheres to collective traditional social relationships, while some 
quarters of UAE society miss this social life, especially with the growing advancement and modernity and the fact that people are preoccupied by the requirement of the modern age.

\section{Fourth}

The motivations for using the Internet were similar in both countries. Percentages were almost similar in terms of using the web to fill leisure time and to develop skills. However, there was slight difference when it comes to fulfilling the requirements of the age and looking for social life where the percentage was remarkably higher for UAE women than Omani women amounting to $90 \%$ to $65 \%$ respectively. This state of affairs is attributable to the fact that the Omani society is still keen to maintain the traditional social life, which makes the Omani women less inclined to use the Internet for this purpose.

\section{Fifth}

1- For the hypotheses of the study, women in both countries agreed (50\% for UAE and 55\% for Oman) that their use of the Internet reduced the time of watching television or listening to the radio. This may be attributable to the fact that the Internet offers a lot of audio-visual material. Therefore, they can watch both the TV and the radio through the web.

2- Women in both countries agreed that the advantages of the Internet are more than the disadvantages, with close percentages of $55 \%$ for UAE women and $65 \%$ for their Omani counterparts.) This shows the positive views of both UAE and Omani women towards, the new technology and its uses.

3- In terms of the contribution of the Internet in increasing woman's information about the outside world, women in both the United Arab Emirates and Oman indicated that the Internet has increased their knowledge about the outside world by about $95 \%$ for the UAE women and $80 \%$ for their Omani counterparts. This shows how the Internet can play an important role in providing information to users.

4- The use of the Internet has increased women's awareness of their causes. Women in the UAE and Oman agreed that the Internet has played an important role in raising their awareness of women's causes in the Arab world by about $75 \%$ for UAE women and 55\% for their Omani counterparts. This shows that the Internet is able to increase women's awareness of their causes. This requires that more attention should be given to this important means of communications by women institutions and organizations, so that it can be best exploited in this respect and in attracting more attention to women issues.

\section{Answering the Study Questions}

\section{Q1: What are forms of women's use of the Internet?}

The Internet plays an important role in women's life in both countries. Women deal with this web in a daily manner and for 3-4 hours at different times by day and night. They use the Internet in workplaces and at homes. This may be attributed to the fact that traditions do not allow women to use the internet in cafes or public places.

\section{What are the websites mostly visited by Arab women?}

The study showed that the websites, which are mostly visited by women in the United Arab Emirates and the Sultanate of Oman are cultural, social, women and scientific websites.

\section{What are the issues that attract women when they use the Internet?}

The study showed that women in the United Arab Emirates and the Sultanate of Oman focus on social and religious issues. This is a natural phenomenon in a Gulf Arab society, where religion plays an important and crucial role.

\section{Is there any difference in UAE and Omani women's use of the Internet?}

The study showed that there is no big difference in the use of the Internet in both countries. There are even similarities in how women in UAE and the Sultanate of Oman use the Internet in terms of their motives, the websites they visit and the issues they focus on. There were minor differences in times and places of using the Internet.

\section{What are the characteristics of the Arab women who use the Internet?}

Women who use the Internet in both the United Arab Emirates and the Sultanate of Oman are young, educated and working. Most women of the sample are married and have social responsibilities.

\section{References}

1. Ali Abdel Mo'ti, Al-Seriaqosi M (1988) The Manners of scientific research Alfalah bookshop for publishing, Kuwait.

2. Ahmed Fahmi (1998) Egyptian Youth using Internet. A paper presented to the fourth annual conference for Mass Communication College. Cairo University, Egypt.

3. Nagwa Abdel Salam (1998) The manners and reasons of Egyptian youth to use the Internet. A paper presented to the fourth annual conference for Mass Communication College. Cairo University, Egypt.

4. Mervat Mohamed Al-Tarabishi (1999) The facts that affect the dealing of Egyptian youth with internet. Journal of college of literature. Helwan University, Egypt.

5. Sameh Abdel Ra'ouf Taie (2001) Using Internet in Arab World. The Egyptian Journal for Public Opinion studies 4

6. Yaqoub Al-Kandary and Hamoud Al- Qash'an (2001) The impact of using internet on the social isolation of Kuwaiti youth. Journal of college of humanities and social sciences 14: 1.

7. Berlent Qabil (2000) The impact of the characters on the communication activities. Cairo University, Mass communication College, Egypt.

8. Ameen Saeed (2003) The Impact of using of Internet on the Youth's values and Ethic. A paper presented to the Ninth annual conference for Mass Communication college. Cairo University, Egypt.

9. Hatem Mohamed Atef (2004) The relation between using internet and the culture identity. The Institution of high children studies.

10. Qirat M , Ayesh M (2006) Use and gratification of the internet: a field and analysis study of UAE youth. A paper presented on the Sharjah forum. The Sharjah cultural department, UAE.

11. Naser Al-Ayadi (2006) UAE Youth and Internet: A field study for using internet and its impact on the cultural behaviors. A paper presented on the Sharjah forum. The Sharjah cultural department. UAE.

12. Lauri M (1997) A Uses and Gratifications Approach to Internet Use in Malta.

13. New Hagen E, Rafaeli S (1998) Why Communication Researchers Should Study the Internet. Journal of Communication 64: 4.

14. Imel S (1998) Serious in Cyber Space Trends and Issues, Alarts, Eric Cleaving House on Adults carrier and Van Cational Education, Climbs us Oh. Office of Education Research 